\title{
Pengaruh Kecerdasan Emosional dan Motivasi Berprestasi Terhadap Minat Belajar Mahasiswa Akuntansi Pada Mata Kuliah Statistika di Universitas Pamulang
}

\author{
Nelly Budiyarti \\ Akuntansi, Fakultas Ekonomi, Universitas Pamulang, nellybudiyarti@gmail.com
}

\begin{abstract}
INFO ARTIKEL
Riwayat Artikel:

Diterima: 12-09-2017

Disetujui: 31-09-2017

\section{Kata Kunci:}

Emotional Intelegence Achievement motivation Interest of learning
\end{abstract}

\section{A. PENDAHULUAN}

Prestasi belajar mahasiswa menjadi salah satu faktor keberhasilan mahasiswa dalam proses mendapatkan kerja dan peningkatan karier. Dalam mencapai prestasi belajar yang tinggi, tentunya diperlukan kesungguhan mahasiswa selama proses belajar mengajar di bangku perkuliahan. Kesungguhan mahasiswa dalam belajar biasanya dapat diamati langsung dengan memperhatikan seberapa besar minat mahasiswa dalam mempelajari suatu bidang keilmuan.

Minat belajar mahasiswa cenderung mengalami fluktuasi karena dipengaruhi oleh beberapa faktor. Faktorfaktor yang dimaksud adalah kecerdasan emosional, motivasi berprestasi, dan sebagainya. Merujuk pada faktor kecerdasan emosional, kaitannya dengan minat belajar adalah ketika secara emosional mahasiswa cenderung menyukai suatu bidang ilmu tanpa memandang tingkat kesulitan dari segi pemahaman dan aplikasinya. Sedangkan motivasi berprestasi dipercaya mampu meningkatkan minat belajar mahasiswa, oleh karena mahasiswa sebagai pribadi cenderung selalu ingin mendapatkan pengakuan dari lingkungannya sebagai pribadi yang berprestasi.

Adapun identifikasi masalah penelitian, yakni sebagai berikut:

a. Minat belajar mahasiswa rendah akibat kurang adanya motivasi untuk meraih prestasi belajar yang lebih baik.

b. Minat belajar mahasiswa rendah karena kurangnya pengetahuan mahasiswa tentang manfaat dan kegunaan mempelajari ilmu Statistika.

c. Mahasiswa kurang cerdas secara emosional karena kurang mampu memecahkan masalah Statistika sehingga tidak menaruh minat pada Statistika. 
d. Dosen sulit mendorong motivasi berpestasi mahasiswa akibat tidak adanya perangkingan sehingga berakibat tidak adanya kompetisi di antara mahasiswa untuk meraih prestasi yang lebih baik.

e. Dosen cenderung hanya terfokus pada kegiatan belajar mengajar tanpa menjelaskan aplikasi statistika untuk kepentingan mahasiswa ke depannya.

f. Mahasiswa kurang menyukai cara mengajar dosen, sehingga berpengaruh pada menurunnya semangat belajar.

g. Mahasiswa kurang menyukai dosen pengajar sehingga secara emosional mahasiswa kurang memperhatikan dan menyimak penjelasan dosen ketika kegiatan belajar mengajar berlangsung.

Tujuan penelitian ini dilakukan untuk menganalisis, menguji dan mengetahui: 1) Pengaruh langsung positif kecerdasan emosional terhadap minat belajar mahasiswa Akuntansi pada mata kuliah Statitstika I di Universitas Pamulang. 2)Pengaruh langsung positif motivasi berprestasi terhadap minat belajar mahasiswa Akuntansi pada mata kuliah Statitstika I di Universitas Pamulang. 3) Pengaruh langsung positif kecerdasan emosional terhadap motivasi berprestasi mahasiswa Akuntansi pada mata kuliah Statitstika I di Universitas Pamulang.

Manfat penelitian ini adalah 1) secara teoris, hasil penelitian ini diharapkan dapat memperkaya referensi bagi ilmu pengetahuan pada umumnya yang berkaitan dengan teori-teori minat belajar, kecerdasan emosional, dan motivasi berprestasi mahasiswa serta bagi pengembangan ilmu kependidikan khususnya. 2) secara praktis, hasil penelitian ini diharapkan bermanfaat bagi peneliti sendiri yakni bertambahnya wawasan pengetahuan yang berkaitan dengan ilmu kependidikan mengenai konsep-konsep minat belajar, kecerdasan emosional, dan motivasi berprestasi mahasiswa dan berguna praktis untuk Program Studi Akuntansi di Lingkungan Universitas Pamulang.

\section{B. LANDASAN TEORI}

\section{Minat Belajar}

Minat belajar adalah suatu kerangka mental yang terdiri dari kombinasi gerak perpaduan dan campuran dari perasaan, prasangka, cemas dan kecenderungankecenderungan, lain yang biasa mengarahkan individu kepada suatu pilihan tertentu. Menurut Belly, minat adalah keinginan yang didorong oleh suatu keinginan setelah melihat, mengamati dan membandingkan serta mempertimbangkan dengan kebutuhan yang diinginkannya [1].

Menurut Slameto dalam Ali Imron beberapa indikator minat belajar yaitu: perasaan senang, ketertarikan, penerimaan, dan keterlibatan mahasiswa. Dari beberapa definisi yang dikemukakan mengenai indikator minat belajar tersebut diatas, dalam penelitian ini menggunakan indikator minat yaitu [2]:
a. Perasaan Senang
b. Perhatian dalam Belajar
c. Bahan mata kuliah dan sikap dosen
d. Manfaat dan Fungsi Mata kuliah

\section{Kecerdasan Emosional}

Henry E. Meyer, kecerdasan emosional adalah kemampuan khusus untuk membaca perasaan terdalam orang-orang yang kita hadapi. Dengan maksud mengatasi orang lain dengan efektif dan strategis [3].

Kecerdasan emosional dapat dikelompokkan menjadi lima area, yaitu sebagai berikut [4]:

a. Kesadaran diri

Yakni mengamati diri sendiri dan mengenali perasaan sejalan dengan perasaan yang terjadi.

b. Pengaturan emosi

Yakni mengendalikan perasaan agar sesuai dan merealisasikan apa yang terdapat dibalik perasaan tersebut, menemukan cara-cara untuk mengendalikan ketakutan dan kecemasan, kemarahan, dan kesedihan.

c. Memotivasi pengaturan diri

Yakni menyalurkan emosi untuk mencapai tujuan dengan melakukan kontrol emosi diri, menunda gratifikasi dan menghambat impuls.

d. Empati

Yakni sensitivitas yang tinggi terhadap perasaan dan perhatian orang lain dan mengadaptasi perspektif mereka, mengapresiasikan berbagai perbedaan mengenai cara orang lain merasakan sesuatu.

e. Pengaturan hubungan

Yakni mengendalikan emosi dalam diri orang lain, keterampilan dan kompetensi sosial.

\section{Motivasi Berprestasi}

Achievement Motivation adalah kebutuhan untuk berhasil, untuk melakukan lebih baik dari lainnya dan untuk menguasai tugas menantang. Hal tersebut adalah hasrat untuk mengatasi, terutama dalam persaingan dengan lainnya. McClelland menyatakan bahwa orang dengan motivasi berprestasi tinggi akan dipaksa lebih sering dahulu untuk mengaksi persoalan sendiri daripada orang yang motivasi berprestasinya rendah. Sedangkan Atkinson mengemukakan bahwa orang yang rendah motivasi berprestasinya akan lebih termotivasi oleh ketakutan akan kegagalan daripada kalah atau cenderung untuk menikmati sukses [5].

Adapun dimensi dan indikator dari variabel motivasi berprestasi antara lain [6]:

a. Kerja keras, indikatornya terdiri dari: Berusaha unggul, dan menyelesaikan tugas dengan baik.

b. Dorongan, indikatornya terdiri dari: rasional dalam meraih keberhasilan.

c. Prestasi, indikatornya terdiri dari: menyukai tantangan.

d. Pengaturan tugas, indikatornya terdiri dari: menerima tanggung jawab pribadi untuk sukses.

e. Kebutuhan dan tanggung jawab, indikatornya terdiri dari: menyukai situasi pekerjaan dengan tanggung jawab pribadi, umpan balik, dan resiko tingkat menengah

\section{Kerangka Pemikiran}

Berdasarkan latar belakang permasalahan, perumusan masalah, tujuan penelitian, dan landasan teori yang telah dikemukakan diatas maka hubungan antar variabel dalam penelitian ini dapat dinyatakan 
dalam sebuah kerangka pemikiran teoritis. Kerangka pemikiran teoritis dapat ditunjukkan oleh model Gambar 1 sebagai berikut :

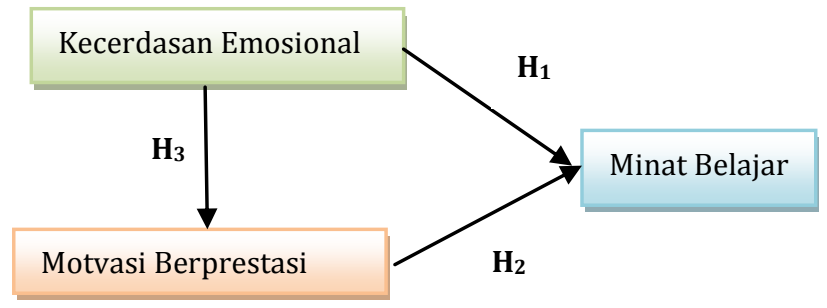

Gambar 1. Kerangka Berpikir

\section{METODE PENELITIAN}

\section{Tempat dan Waktu Penelitian}

Tempat penelitian adalah Program Studi Akuntansi Universitas Pamulang, dengan alamat jalan Surya Kencana Kencana No. 1 Tangerang, Indonesia.Pendekatan penelitian ini berdasarkan pendekatan survei. Penelitian survey adalah penelitian yang mengambil sampel dari satu populasi dan menggunakan kuesioner sebagai alat pengumpulan data yang pokok dan mengumpulkan data mengenai faktor-faktor yang berkaitan dengan variabel penelitian.

Jenis penelitian adalah kuantitatif yakni dengan menggunakan data-data skor jawaban responden.Penelitian memakan waktu 6 bulan dimulai pada awal Juni 2017 sampai dengan akhir Agustus 2017. Dalam waktu 3 bulan tersebut dimulai dari persiapan, survey, penyusunan proposal, uji coba instrumen, pengambilan data sampai dengan analisis data dan penyusunan laporan akhir.

\section{Populasi dan Sampel}

Populasi target dalam penelitian ini adalah seluruh mahasiswa pada Fakultas Ekonomi Program Studi Akuntansi Strata Satu (S1). Sedangkan yang termasuk dalam populasi terjangkau adalah mahasiswa semester IV Fakultas Ekonomi Program Studi Akuntansi Strata Satu. Jumlah kelas di semester IV adalah 10 kelas dengan total keseluruhan jumlah mahasiswa adalah 326 orang mahasiswa.

Penetapan jumlah sampel penelitian menggunakan uji Slovin, dari jumlah populasi pada obyek yang akan diteliti, maka jumlah sampel pada penelitian ini ditentukan dengan margin kesalahan $0,05 \%$ sehingga didapatkan sampel sebesar 180 orang dari jumlah populasi 326 orang mahasiswa [9].

Pemilihan sampel penelitian dilakukan dengan metode proposional sampel [10].

\section{Metode Pengumpulan Data}

Teknik pengumpulan data dengan menggunakan angket. Angket atau instrumen yang dipakai dalam penelitian ini berupa kuesioner sebagai alat untuk mengetahui keadaan responden, kemudian butir-butir kuesioner tersebut akan dijawab oleh responden, dalam hal ini adalah mahasiswa semester IV pada Program Studi Akuntansi (S1) Fakultas Ekonomi Universitas Pamulang. Instrumen tersebut digunakan untuk mengukur variabel Minat Belajar Mahasiswa sebagai variabel yang dipengaruhi $\left(\mathrm{X}_{3}\right)$, dan variabel yang memiliki pengaruh terhadap minat belajar mahasiswa seperti Kecerdasan Emosional $\left(\mathrm{X}_{1}\right)$ dan Motivasi Berprestasi $\left(\mathrm{X}_{2}\right)$, maka penulis menyusun instrumen melalui beberapa tahap yaitu:

a. Mengkaji semua teori yang berkaitan dengan variabel-variabel yang akan diteliti.

b. Melakukan analisa variabel tersebut menjadi beberapa sub variabel atau dimensi variabel, lalu kembangkan indikator setiap dimensinya.

c. Menyusun kisi-kisi.

d. Menyusun butir-butir pernyataan dan menetapkan skala pengukuran.

e. Uji coba instrumen.

f. Analisis butir soal dengan menguji validitas dan reliabilitas.

\section{Teknik Analisis Data}

Analisis data menggunakan uji statistik Path Analisys, dimana analisis jalur adalah melihat pengaruh dari matrik korelasi. Penelitian ini menggunakan tiga instrumen yang berasal dari kajian teoretis dan instrumen tersebut telah diadakan uji coba untuk mengetahui validitasnya.

\section{a. Uji Klasi Data}

1) Uji Normalitas Galat Taksiran

2) Uji Homogenitas

\section{b. Uji Hipotesis}

1) Uji korelasi Sederhana

Tehnik korelasi sederhana yang digunakan adalah korelasi Pearson Product Moment. Tujuan uji korelasi ini adalah untuk mengetahui hubungan antara variabel-variabel bebas dengan terikatnya. Rumus Product Moment Pearson, yakni sebagai berikut [11]:

$$
r_{x y}=\frac{n\left(\sum X Y\right)-\left(\sum X\right)\left(\sum Y\right)}{\sqrt{\left\{n\left(\sum X^{2}\right)-\left(\sum X\right)^{2}\right\}} \sqrt{n \sum Y^{2}-\left(\sum Y\right)^{2}}}
$$

2) Ujit

Untuk menilai t hitung digunakan rumus [12]:

$$
t=r \sqrt{\frac{n-2}{1-r^{2}}}
$$

3) Uji Analisis Jalur

Untuk mengkaji adanya pengaruh antar variabel terikat $\left(\mathrm{X}_{3}\right)$ dan variabel bebas $\left(\mathrm{X}_{1}\right.$ dan $\mathrm{X}_{2}$ ) guna melihat keeratan antara endogen (yang mempengaruhi) terhadap variabel eksogen (yang dipengaruhi). Untuk mengetahui tingkat pengaruh jalur yang terkait dengan koefisien korelasi dapat dilakukan sebagai berikut [12]:

Realisasi matrik korelasi analisis jalur

\begin{tabular}{|c|c|c|c|}
\hline & $\mathbf{X}_{\mathbf{1}}$ & $\mathbf{X}_{\mathbf{2}}$ & $\mathbf{X}_{\mathbf{3}}$ \\
\hline $\mathrm{X}_{1}$ & 1 & & \\
\hline $\mathrm{X}_{2}$ & & 1 & \\
\hline $\mathrm{X}_{3}$ & & & 1 \\
\hline
\end{tabular}

Dari persamaan 1 sampai 3

$$
\begin{aligned}
& \mathrm{r}_{12}=\mathrm{P}_{21} \ldots \ldots \ldots \ldots \ldots \ldots \ldots \ldots \ldots \ldots \ldots \ldots \ldots \ldots \ldots \ldots \ldots \ldots \ldots \ldots \ldots \ldots \ldots \ldots \ldots \ldots \ldots \ldots \\
& \mathrm{r}_{13}
\end{aligned}
$$


$r_{23}=P_{31} r_{12}+p_{32} \ldots \ldots \ldots \ldots \ldots \ldots \ldots \ldots .3$

Dengan mengetahui koefisien korelasi setiap data penelitian maka dari persamaan 1,2, dan 3 diperoleh p21, p31, dan p32. Kriteria pengujiannya adalah bila nilai $\mathrm{p}>0,05$, hasilnya signifikan dan kesimpulannya terdapat pengaruh antar variabel penelitian.

\section{HASIL DAN PEMBAHASAN}

\section{Deskripsi Data}

Mengkomunikasikan dan mendeskripsikan data hasil penelitian merupakan langkah yang erat kaitannya dengan kegiatan analisis data sebagai prasyarat untuk memasuki tahap pembahasan dan juga mengambil kesimpulan hasil penelitian. Data yang berhasil dihimpun sejak bulan Juni 2017 sampai Agustus 2017 di Program Studi Akuntansi Fakultas Ekonomi Universitas Pamulang berasal dari 180 orang mahasiswa semester IV sebagai sampel penelitian.

Respon yang diberikan pada setiap variabel penelitian menjadi dasar untuk analisis lebih lanjut dalam penelitian ini. Gambaran menyeluruh mengenai statistik deskriptif untuk semua data variabel penelitian disajikan pada tabel berikut ini:

TABEL 1

PENYAJIAN STATISTIK DESKRIPTIF VARIABEL PENELITIAN

\begin{tabular}{|c|c|c|c||c||c||c||c||}
\hline Var & Max & Min & Mean & SD & S & Mo & Me \\
\hline \hline $\mathrm{X}_{3}$ & 120 & 66 & 92,93 & 13,4 & 179,4 & 103 & 93 \\
\hline \hline $\mathrm{X}_{1}$ & 115 & 24 & 81,33 & 16,9 & 284,6 & 62 & 80 \\
\hline \hline $\mathrm{X}_{2}$ & 110 & 34 & 78,06 & 13,7 & 188 & 92 & 82 \\
\hline
\end{tabular}

Keterangan:

$\mathrm{X}_{3}$ : Minat Belajar

$\mathrm{X}_{1}$ : Kecerdasan Emosional

$\mathrm{X}_{2}$ : Motivasi Berprestasi

\section{Uji Klasik Data}

a. Uji Normalitas Galat Taksiran

Pengujian ini dimaksudkan untuk menguji apakah galat baku taksiran regresi $(\mathrm{X}-\widetilde{\mathrm{XX}})$ berdistribusi normal atau tidak. Ketentuan pengujian adalah taksiran $(\mathrm{X}-\widehat{\mathrm{X}} \mathrm{X})$ berdistribusi normal jika Ho diterima dan tidak berdistribusi normal jika Ho ditolak.

Statistik yang digunakan untuk menguji normalitas adalah dengan menggunakan Uji Lilliefors (L) Galat Taksiran dengan ketentuannya jika Lhitung $<\mathrm{L}_{\text {tabel }}$ maka terima Ho dan jika Lhitung $>$ $\mathrm{L}_{\text {tabel }}$ maka tolak Ho.

1) Uji Normalitas Galat Baku Taksiran $X_{3}$ atas $X_{1}$

Berdasarkan persamaan regresi $\widehat{\mathrm{X}}_{3} \widehat{\mathrm{X}}_{3}=54,03+$ $0,50 \mathrm{X}_{1}$ dapat dihitung nilai $\widehat{\mathrm{X}} \widehat{\mathrm{X}}$ dengan bantuan komputer selanjutnya dihitung pula nilai $\mathrm{Z}$, $\mathrm{F}\left(\mathrm{Z}_{1}\right)$, dan $\mathrm{S}\left(\mathrm{Z}_{1}\right)$. Dapat diketahui $\mathrm{L}=\mathrm{F}\left(\mathrm{Z}_{1}\right)-\mathrm{S}$ $\left(Z_{1}\right)$, L hitung diambil nilai tertinggi. Dari hasil perhitungan diperoleh $\mathrm{L}_{\text {hitung }}=0,0477$ sedangkan $\mathrm{L}_{\text {tabel }}(0,05)=0,0660$. Jadi $\mathrm{L}_{\text {hitung }}<\mathrm{L}_{\text {tabel }}$ sehingga Ho diterima. Hal ini berarti bahwa hipotesis nol diterima, dengan demikian galat baku taksiran dari persamaan regresi $\widehat{\mathrm{X}}_{3} \widehat{\mathrm{X}}_{3}=54,03+$ $0,50 \mathrm{X}_{1}$ berdistribusi normal.

2) Uji Normalitas Galat Baku Taksiran $X_{3}$ atas $X_{2}$

Berdasarkan persamaan regresi $\widehat{\mathrm{X}}_{3} \widehat{\mathrm{X}}_{3}=50,83+$ $0,52 \mathrm{X}_{2}$ dapat dihitung $\widetilde{\mathrm{XX}}$ nilai, dengan bantuan komputer selanjutnya dihitung pula nilai $\mathrm{Z}$, $\mathrm{F}\left(\mathrm{Z}_{1}\right)$, dan $\mathrm{S}\left(\mathrm{Z}_{1}\right)$. Dapat diketahui $\mathrm{L}=\mathrm{F}\left(\mathrm{Z}_{1}\right)$ $\mathrm{S}\left(\mathrm{Z}_{1}\right)$, Lhitung diambil nilai tertinggi. Dari hasil perhitungan diperoleh $\mathrm{L}$ hitung $=0,0443$ sedangkan $L$ tabel $(0,05)=0,0660$. Jadi $L_{\text {hitung }}<$

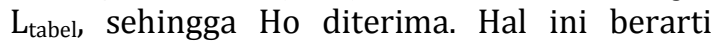
bahwa hipotesis nol diterima, dengan demikian galat baku taksiran dari persamaan regresi $\widehat{\mathrm{X}}_{3}$ $\widehat{\mathrm{X}}_{3}=50,83+0,52 \mathrm{X}_{2}$ berdistribusi normal.

3) Uji Normalitas Galat Baku Taksiran $X_{2}$ atas $X_{1}$

Berdasarkan persamaan regresi $\widehat{\mathrm{X}}_{2} \widehat{\mathrm{X}}_{2}=48,94+$ $0,41 \mathrm{X}$, dapat dihitung nilai $\widehat{\mathrm{XX}}$, dengan bantuan komputer selanjutnya dihitung pula nilai $\mathrm{Z}$, $\mathrm{F}\left(\mathrm{Z}_{1}\right)$, dan $\mathrm{S}\left(\mathrm{Z}_{1}\right)$. Dapat diketahui $\mathrm{L}=\mathrm{F}\left(\mathrm{Z}_{1}\right)$ $\mathrm{S}\left(\mathrm{Z}_{\mathrm{i}}\right), \mathrm{L}_{\text {hitung }}$ diambil nilai tertinggi. Dari hasil perhitungan diperoleh L Litung $=0,0377$ sedangkan $\mathrm{L}_{\text {tabel }}(0,05)=0,0660$. Jadi $\mathrm{L}_{\text {hitung }}<$ $\mathrm{L}_{\text {tabel }}$ sehingga Ho diterima. Hal ini berarti bahwa hipotesis nol diterima, dengan demikian galat baku taksiran dari persamaan regresi $\widehat{\mathrm{X}}_{2}$ $\widehat{\mathrm{X}}_{2}=48,93+0,41 \mathrm{X}_{1}$ berdistribusi normal.

b. Uji Homogenitas

Rumus Barlett digunakan untuk menghitung uji homogenitas varians gabungan data variabel minat belajar berdasarkan pengelompokkan data variabel kecerdasan emosional $\left(\mathrm{X}_{3}\right.$ atas $\left.\mathrm{X}_{1}\right)$ dengan syarat $\chi \mathrm{h}^{2}<\chi^{2}$. Begitu pula rumus Barlett digunakan untuk menghitung uji homogenitas varian gabungan data variabel minat belajar berdasarkan pengelompokkan data variabel motivasi berprestasi $\left(\mathrm{X}_{3}\right.$ atas $\left.\mathrm{X}_{2}\right)$ dengan syarat $\chi \mathrm{h}^{2}<\chi^{2}$, dan uji homogenitas varian gabungan data variabel motivasi berprestasi berdasarkan pengelompokkan data variabel kecerdasan emosional $\left(\mathrm{X}_{2}\right.$ atas $\left.\mathrm{X}_{1}\right)$ dengan syarat $\chi \mathrm{h}^{2}<\chi \mathrm{t}^{2}$. [14].

Hasil perhitungan homogenitas disajikan dalam bentuk Tabel 2 berikut ini:

TABEL 2

RANGKUMAN HASIL PERHITUNGAN UJI HOMOGENITAS.

\begin{tabular}{||c|c|c|c|}
\hline Varians & $\chi \mathrm{h}^{2}$ & $\chi^{\mathrm{t}^{2}}$ & Kesimpulan \\
\hline $\mathrm{X}_{3}$ atas $\mathrm{X}_{1}$ & 37,11 & 46,5 & Homogen \\
\hline \hline $\mathrm{X}_{3}$ atas $\mathrm{X}_{2}$ & 27,42 & 37,7 & Homogen \\
\hline \hline $\mathrm{X}_{2}$ atas $\mathrm{X}_{1}$ & 44,23 & 46,5 & Homogen \\
\hline
\end{tabular}

\section{Uji Hipotesis}

\section{a. Uji Korelasi Sederhana}

1) Pengaruh Kecerdasan Emosional ( $\left.X_{1}\right)$ terhadap Minat Belajar $\left(\mathrm{X}_{3}\right)$ 
TABEL 3

UJI SIGNIFIKANSI KOEFISIEN KORELASI

ANTARA KECERDASAN EMOSIONAL $\left(\mathrm{X}_{1}\right)$ DENGAN MINAT BELAJAR $\left(\mathrm{X}_{3}\right)$

\begin{tabular}{|c|c|c|c|c||}
\hline $\mathrm{dk}$ & \multirow{2}{*}{$\begin{array}{c}\text { Koefisien } \\
\text { Korelasi } \\
\left(\mathrm{r}_{13}\right)\end{array}$} & $\mathrm{t}_{\text {hitung }}$ & \multicolumn{2}{|c|}{$\mathrm{t}_{\text {tabel }}$} \\
\cline { 4 - 5 } & & 0,975 & 0,995 \\
\hline \hline 180 & 0,6275 & 10,59 & 1,96 & 2,58 \\
\hline
\end{tabular}

Tingkat keeratan hubungan antara Kecerdasan Emosional $\left(\mathrm{X}_{1}\right)$ dengan Minat Belajar $\left(\mathrm{X}_{3}\right)$ ditunjukkan oleh Koefisien Korelasi $\left(r_{13}\right)$ sebesar 0,6275 . Berdasarkan uji signifikansi koefisien korelasi dengan menggunakan uji-t diperoleh harga $t_{\text {hitung }}=$ $10,59>t_{\text {tabel }(0,975 ; 99)}=1,96$, maka dapat disimpulkan bahwa koefisien korelasi signifikan sehingga kecerdasan emosional memiliki hubungan positif dengan minat belajar.

2) Pengaruh Motivasi Berprestasi ( $\left.X_{2}\right)$ terhadap Minat Belajar $\left(\mathrm{X}_{3}\right)$

TABEL 4

UJI SIGNIFIKANSI KOEFISIEN KORELASI ANTARA MOTIVASI BERPRESTASI $\left(\mathrm{X}_{2}\right)$ DENGAN MINAT BELAJAR $\left(\mathrm{X}_{3}\right)$

\begin{tabular}{|c|c||c||c|c||}
\hline \multirow{2}{*}{$\mathrm{dk}$} & \multirow{2}{*}{$\begin{array}{c}\text { Koefisien } \\
\left.\text { Korelasi ( } \mathrm{r}_{13}\right)\end{array}$} & \multirow{2}{*}{$\mathrm{t}_{\text {hitung }}$} & \multicolumn{2}{|c|}{$\mathrm{t}_{\text {tabel }}$} \\
\cline { 5 - 5 } & & 0,975 & 0,995 \\
\hline \hline 180 & 0,5299 & $8,32^{* *}$ & 1,96 & 2,58 \\
\hline
\end{tabular}

Tingkat keeratan hubungan antara Motivasi Berprestasi $\left(\mathrm{X}_{2}\right)$ dengan Minat Belajar $\left(\mathrm{X}_{3}\right)$ ditunjukkan oleh Koefisien Korelasi $\left(\mathrm{r}_{13}\right)$ sebesar 0,5299. Berdasarkan uji signifikansi koefisien korelasi dengan menggunakan uji$\mathrm{t}$ diperoleh harga $\mathrm{t}_{\text {hitung }}=8,32>\mathrm{t}_{\text {tabel }}(0,975 ; 99)$ $=1,96$, maka dapat disimpulkan bahwa koefisien korelasi signifikan sehingga motivasi berprestasi memiliki hubungan positif dengan minat belajar.

3) Pengaruh Kecerdasan Emosional $\left(X_{1}\right)$ terhadap Motivasi Berprestasi $\left(\mathrm{X}_{2}\right)$ TABEL 5

UJI SIGNIFIKANSI KOEFISIEN KORELASI ANTARA KECERDASAN EMOSIONAL $\left(\mathrm{X}_{1}\right)$ DENGAN MOTIVASI BERPRESTASI $\left(\mathrm{X}_{2}\right)$

\begin{tabular}{|c|c|c|c|c|}
\hline \multirow{2}{*}{$\mathrm{dk}$} & \multirow{2}{*}{$\begin{array}{c}\text { Koefisien } \\
\left.\text { Korelasi ( } \mathrm{r}_{12}\right)\end{array}$} & $\mathrm{t}_{\text {hitung }}$ & \multicolumn{2}{|c|}{$\mathrm{t}_{\text {tabel }}$} \\
\cline { 4 - 5 } & & 0,975 & 0,995 \\
\hline 180 & 0,5104 & $7,92^{* *}$ & 1,96 & 2,58 \\
\hline
\end{tabular}

Tingkat keeratan hubungan antara Kecerdasan Emosional $\left(\mathrm{X}_{1}\right)$ dengan Motivasi Berprestasi $\left(\mathrm{X}_{2}\right)$ ditunjukkan oleh Koefisien Korelasi $\left(r_{12}\right)$ sebesar 0,5104. Berdasarkan uji signifikansi koefisien korelasi dengan menggunakan uji-t diperoleh harga $t_{\text {hitung }}=7,92>t_{\text {tabel }(0,975 ; 99)}=$ 1,96, maka dapat disimpulkan bahwa koefisien korelasi signifikan sehingga kecerdasan emosional memiliki hubungan positif dengan motivasi berprestasi.

\section{Uji Analisis Jalur}

\section{a. Konstelasi Skema Penelitian}

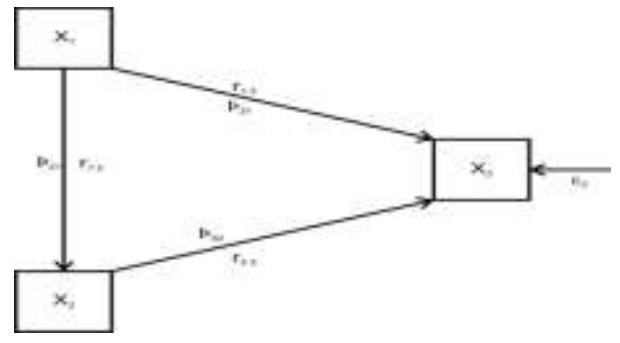

Gambar 2. Diagram Jalur Hubungan Kausal Empiris $\mathrm{X}_{1}$ dan $\mathrm{X}_{2}$ terhadap $\mathrm{X}_{3}$

\section{b. Hasil Uji Analisis Jalur}

TABEL 6

UJI ANALISIS JALUR

\begin{tabular}{|c|c|c|c|}
\hline $\begin{array}{c}\text { Koefisien } \\
\text { nalisis } \\
\text { Jalur }\end{array}$ & Hasil Uji & Signifikansi & Keterangan \\
\hline $\mathrm{p}_{31}$ & 0,4828 & 0,05 & Signifikans \\
\hline $\mathrm{p}_{32}$ & 0,2834 & 0,05 & signifikans \\
\hline $\mathrm{p}_{21}$ & 0,5104 & 0,05 & signifikans \\
\hline
\end{tabular}

Dengan demikian hasil yang diperoleh adalah koefisien jalur $X_{1}$ ke $X_{3}$ atau $b_{31}=0,4828$ dan koefisien jalur $X_{2}$ ke $X_{3}$ atau $p_{32}=0,2834$. Karena nilai koefisien jalur $>0,05$ maka koefisien analisis jalur signifikans.

Berdasarkan koefisien jalur tersebut, maka persamaan jalurnya dapat dibuat sebagai berikut : $\mathrm{X}_{3}=\mathrm{p}_{31} \mathrm{X}_{1}+\mathrm{p}_{32} \mathrm{X}_{2}+\mathrm{p} \varepsilon_{3}$ menjadi : $\mathrm{X}_{3}=$ $0,0,4828 \mathrm{X}_{1}+0,2834 \mathrm{X}_{2}+\mathrm{px} \varepsilon_{3}$.

Berdasarkan hasil perhitungan analisis jalur yang telah dijabarkan sebelumnya, maka memberikan informasi secara obyektif sebagai berikut:

1. Besarnya pengaruh kecerdasan emosional $\left(X_{1}\right)$ yang secara langsung terhadap minat belajar $\left(\mathrm{X}_{3}\right)$ adalah $0,4828^{2}=0,2331$ atau $23,31 \%$. Artinya kecerdasan emosional memberikan kontribusi langsung terhadap peningkatan minat belajar mahasiswa sebesar $23,31 \%$ dengan mengontrol variabel motivasi berprestasi mahasiswa, dengan kata lain, yakni tanpa diganggu oleh variabel kecerdasan emosional.

2. Besarnya pengaruh motivasi berprestasi $\left(X_{2}\right)$ yang secara langsung terhadap minat belajar $\left(\mathrm{X}_{3}\right)$ adalah $0,2834^{2}=0,0803$ atau $8,03 \%$. Artinya motivasi berprestasi mahasiswa memberikan kontribusi langsung terhadap peningkatan minat belajar mahasiswa sebesar 8,03\% dengan mengontrol variabel kecerdasan emosional, dengan kata lain, yakni tanpa diganggu oleh variabel kecerdasan emosional.

3. Besarnya pengaruh kecerdasan emosional $\left(X_{1}\right)$ yang secara langsung terhadap motivasi berprestasi $\left(\mathrm{X}_{2}\right)$ adalah $0,5104^{2}=0,2605$ atau $26,05 \%$. Artinya variabel kecerdasan emosional memberikan kontribusi langsung terhadap peningkatan motivasi berprestasi mahasiswa sebesar 26,05 dengan 
mengontrol variabel minat belajar mahasiswa, dengan kata lain, yakni tanpa diganggu variabel minat belajar mahasiswa.

\section{E. SIMPULAN DAN SARAN}

Berikut ini penulis sampaikan beberapa kesimpulan penelitian, yakni sebagai berikut:

1. Pengujian hipotesis pertama bahwa terdapat pengaruh langsung positif kecerdasan emosional terhadap minat belajar mahasiswa, diperoleh $r_{13}$ sebesar 0,6275, dan koefisien analisis jalur $\left(\mathrm{p}_{31}\right)=0,4828$. Hal ini menunjukan bahwa bahwa terdapat pengaruh langsung positif kecerdasan emosional terhadap minat belajar mahasiswa.

2. Pengujian hipotesis kedua bahwa terdapat pengaruh langsung positif motivasi berprestasi terhadap minat belajar mahasiswa, diperoleh koefisien korelasi $r_{23}$ sebesar 0,5299, dan koefisien jalur $\left(\mathrm{b}_{32}\right)=0,2834$. Hal ini menunjukan bahwa terdapat pengaruh langsung positif motivasi berprestasi terhadap minat belajar mahasiswa.

3. Pengujian hipotesis ketiga bahwa terdapat pengaruh langsung positif kecerdasan emosional terhadap motivasi berprestasi, diperoleh koefisien korelasi $\mathrm{r}_{12}=0,5104$, dan koefisien jalur $\left(\mathrm{p}_{21}\right)=$ 0,5104. Hal ini menunjukan bahwa terdapat pengaruh langsung positif kecerdasan emosional terhadap motivasi berprestasi mahasiswa.

Berdasarkan hasil penelitian, penulis ajukan beberapa saran yang dapat berguna untuk memperbaiki diferensiasi produk, komunikasi pemasaran, dan loyalitas konsumen, yakni sebagai berikut:

1. Bagi dosen:

a. Memperbaiki dan meningkatkan profesionalitas dosen, baik dalam hal metode mengajar, materi mengajar, dan sebagainya demi meningkatkan minat belajar mahasiswa.

b. Memberikan dorongan dan kesadaran pada mahasiswa agar mampu meningkatkan minat belajar demi tercapainya tujuan belajar yang baik.

c. Menambah media belajar yang memudahkan mahasiswa untuk lebih memahami Statistika.

d. Materi mengajar lebih dikembangkan ke arah bagaimana pengaplikasian Statistika Terapan untuk penelitian, demi menunjang kegiatan penelitian mahasiswa untuk memperoleh gelar sarjana.

e. Mengembangkan teknik mengajar dengan mengacu pada tingkat pemahaman mahasiswa agar dapat tercapai tujuan belajar mengajar.

2. Bagi mahasiswa:

a. Menumbuhkan dan meningkatkan motivasi diri dalam belajar agar dapat tercapai prestasi belajar yang baik.

b. Cerdas secara emosional, artinya diharapkan mahasiwa dapat mengarahkan diri secara emosional untuk selalu bersikap positif dan optimis selama kegiatan belajar mengajar. Agar tujuan belajar dapat tercapai.

\section{UCAPAN TERIMA KASIH}

Terima kasih saya khaturkan kepada Ketua Program Studi Akuntansi S1 Fakultas Ekonomi Universitas Pamulang, yakni Bapak H. Endang Ruhiyat, S.E., M.M dan seluruh mahasiswa semester 4 Reguler A yang telah banyak membantu dalam proses penyelesaian paper ini.

\section{DAFTAR RUJUKAN}

[1] Andriani, Dian, Upaya meningkatkan minat dan prestasi belajar sejarah melalui penerapan penilaian instan pada siswa kelas XI IPS SMAN Tempel", Skripsi. Fakultas Ilmu Sosial dan Ekonomi. Yogyakarta: Universitas Negeri Yogyakarta, 2010

[2] Belly, Ellya dkk., Pengaruh Motivasi terhadap Minat Mahasiswa Akuntasi, Simposium Nasional Akuntasi 9 Padang, 2006

[3] Goleman, Daniel., Emotional Intelligence. Penerjemah T Hermaya, Jakarta:Gramedi,2003

[4] Meyer, Henry E., Emotional Intelegence: Cara Humanis Memimpin Bisnis, Penerjemah Munir, Bandung:Nuansa, 2011

[5] Atkinson, Jhon W., An Introduction to Motivation, New York: D. Van Nostrand Company, Inc, 1964

[6] McClelland, David C., et al., The Achevement Motivation, New York: Irvington Publisher, 1976

[7] Purwanti, Yatmi., "Meningkatkan minat dan prestasi belajar IPS sejarah melalui penerapan pendekatan pembelajaran Make a Match pada siswa SMPN 4 Gamping", Skripsi, Fakultas Ilmu Sosial dan Ekonomi. Yogyakarta: Universitas Negeri Yogyakarta, 2008

[8] Andriani, Dian., Upaya meningkatkan minat dan prestasi belajar sejarah melalui penerapan penilaian instan pada siswa kelas XI IPS SMAN Tempel", Skripsi, Fakultas Ilmu Sosial dan Ekonomi. Yogyakarta: Universitas Negeri Yogyakarta, 2010

[9] Sugiyono, Metode Penelitian Administrasi, Bandung: Alfabeta, 2005

[10] Soehartono, Irawan., Metode Penelitian Sosial, Bandung Remaja Rosdakarya, 1999

[11] Pedoman Tesis dan Disertasi, Jakarta, Program Pascasarjana Universitas Muhammadiyah Prof.DR. Hamka, 2008

[12] Murwani, Santosa., Statistika Terapan, Jakarta: UHAMKA, 2012

[13] Sunyoto, Danang., Analisis Regresi Dan Uji Hipotesis, Yogyakarta: MedPress, 2009

[14] Hasan, M. Iqbal., Analisis Data Penelitian Dengan Statistik, Jakarta: Bumi Aksara, 2004 